\title{
Discussion on Integrated Modeling Technology of New Generation Centralized Control Station Equipment Monitoring System
}

\author{
Yi ZHAI ${ }^{1}$, Tianpin XU, Qijing YANG, Weihua CAO, Zhichao QI, Chunyao LIU \\ Nari Group Corporation (State Grid Electric Power Research Institute), Nanjing \\ Jiangsu 210061, China
}

\begin{abstract}
At present, the substation SCD model mainly aims at the modeling of primary equipment and secondary equipment, and the description of auxiliary equipment and substation area model is missing. According to the characteristics of equipment monitoring of the new generation centralized control station, the description of auxiliary equipment model and area model needs to be added to the original IEC61850 standard. In the first mock exam station, the current business requirements of centralized control station are analyzed. A unified model structure of master station is designed. Based on the definition of IEC61850 standard, a method and example of extending auxiliary device model and regional model are given. The proposed auxiliary equipment and area modeling method based on IEC61850 standard can make up for the shortcomings of the original standard, support the equipment monitoring of the new generation centralized control station and realize rich application functions.
\end{abstract}

Keywords. IEC61850, SCD, auxiliary equipment, substation area model

\section{Introduction}

At present, the domestic regional dispatching operation mode has been mature and stable, but the operation and management mode for substation monitoring has not been finalized. Different regions have adopted different construction methods due to the different degree of economic and power grid development. At present, there are three main modes of substation monitoring [1]: 1. Substation substation monitoring. 2. The mode of centralized control station adopts the slice monitoring. 3. Centralized control center mode: several operation and maintenance stations with few people on duty are set up

\footnotetext{
${ }^{1}$ Corresponding author: Yi Zhai, Nari Group Corporation (State Grid Electric Power Research Institute), Nanjing Jiangsu 210061, China; E-mail: vitty2005@163.com.
} 
according to the operation radius. One centralized control center can monitor hundreds of substations. At present, this mode can be subdivided into two modes in China: 1 . Separation of dispatching and centralized control. 2. Integration of dispatching and centralized control. At present, $41.1 \%$ of substations in state grid system adopt traditional mode and centralized control station mode. Primary equipment and signal information monitored by the master station are actually modeled in the substation. The master station belongs to repetitive modeling, and does not follow the principle of "source maintenance, resource sharing".

In 2020, the key tasks of the State Grid Corporation are to implement the equipment ownership system, optimize the operation and maintenance mode of the substation according to local conditions, and implement centralized monitoring of the substation. The State Grid equipment department actively implements the company's work requirements, carries out the optimization of substation operation and maintenance monitoring mode, speeds up the construction of substation centralized control station, and improves the main and auxiliary equipment monitoring and other technical support means. Combined with the overall scheme of the new generation of independent and controllable substation secondary system, fully inheriting the construction experience and achievements of the existing dispatching system and auxiliary control system, adhering to the "problem oriented, demand-oriented and goal oriented", this paper puts forward the idea of a new generation of centralized control station monitoring system with main and auxiliary functions.

In summary, these requirements make the data communication between the main and sub stations break the point-to-point forwarding mode, and adopt the main plant station interaction technology which is more flexible, efficient and compatible with the existing communication system, Through the bottleneck of interaction between the two ends, the main station automation system and substation automation system are closely combined from the dimension of application function to realize interconnection of the automation system of the main station [2-5].Since the promulgation and implementation of $\mathrm{q} / \mathrm{gdw} 679$ technical specification for the construction of intelligent substation integrated monitoring system [6], it is proposed that the integrated monitoring system of substation integrates all the subsystems and equipment in the station.

In reference [7-9], seamless communication integrated modeling of main substation and substation and centralized monitoring function design are proposed.

Reference [10] proposed a method to expand the protection information system based on IEC61850 standard, but did not mention how to expand the auxiliary equipment model and substation area model

The purpose of this paper is to discuss the unified modeling of main and auxiliary equipment, and then put forward the idea of how to expand the auxiliary equipment model on the basis of the original SCD standard.

\section{Requirement Analysis of Integrated Modeling}

\subsection{Model Requirements}

For the traditional centralized control and monitoring center, due to the new equipment and new technology of the intelligent substation, the data requirements of the main station system for the substation have new changes, which are no longer limited to the traditional four remote information, but need the operation status information of the 
substation system and equipment (such as the primary and secondary equipment status monitoring information, equipment account and configuration information, model, graphics, protection recording, data processing, Fault recording, network message, auxiliary control equipment and other file information).

Taking the $500 \mathrm{kV}$ Smart Substation in Zhejiang Province as an example, the "regional dispatching information forwarding table" is counted, including 1998 remote signaling and 381 telemetry.

In addition to the above statistics, it also analyzes the specific content of the data sent to the main station by the intelligent substation. The new data are mainly reflected in the following aspects: intelligent terminal, general object-oriented substation event (goose) / sampling value (SV) link signal of merging unit, network switch alarm information, network switch alarm information, and so on at the same time, due to the different business needs of regional and provincial dispatching, many new sending signals are sent in the way of combined point number.

From the above analysis, it can be seen that intelligent substation not only increases the amount of data, but also adds a lot of new types of data. The increase of data is both an opportunity and a challenge for the data analysis application function of main station and substation. On the one hand, multi types of data can provide rich basic data for analysis and calculation applications, Enhance the professional technical level of advanced application function; On the other hand, due to the deployment of a large number of IED in Smart Substation, in the development trend of unattended substation, the operation status of primary and secondary equipment and monitoring system in the station needs convenient remote monitoring and analysis means, but at present most of the data can not be sent, and is stranded in the station, which brings hidden dangers and risks to the reliable monitoring of equipment operation status.

\subsection{Business Requirements}

In terms of business functions of dispatching master station and substation, through the pilot application and construction of intelligent substation, the integrated monitoring system integrates data acquisition and monitoring (SCADA), equipment condition monitoring, protection substation, auxiliary system monitoring and other subsystems, and the system complexity also increases. At present, the dispatching system or centralized monitoring model is manually modeled by the master station. At present, there is no auxiliary device model in the SCD file of the smart substation, and there is no description of such equipment in the IEC61850 specification. Therefore, an example of the figure 1, it is necessary to extend the IEC61850 standard to increase the description of the auxiliary device.

By standardizing the substation model system, integrating the information model of substation, centralized control station and business middle station, and insisting on one source of substation professional data, the information fusion and connection of automation system and information system can be realized.

The first mock exam is based on the unified model. The integration of the primary equipment model, the two equipment models, the auxiliary equipment model, the equipment ledger, and the physical ID is realized in the substation.

Data connection: with the physical ID and equipment account as the link, the connection and transformation between the equipment model and the business platform model are completed in the centralized control station, so as to realize the integration and 
connection between the main and auxiliary equipment monitoring system of the substation and the business platform data.

Centralized control station Model

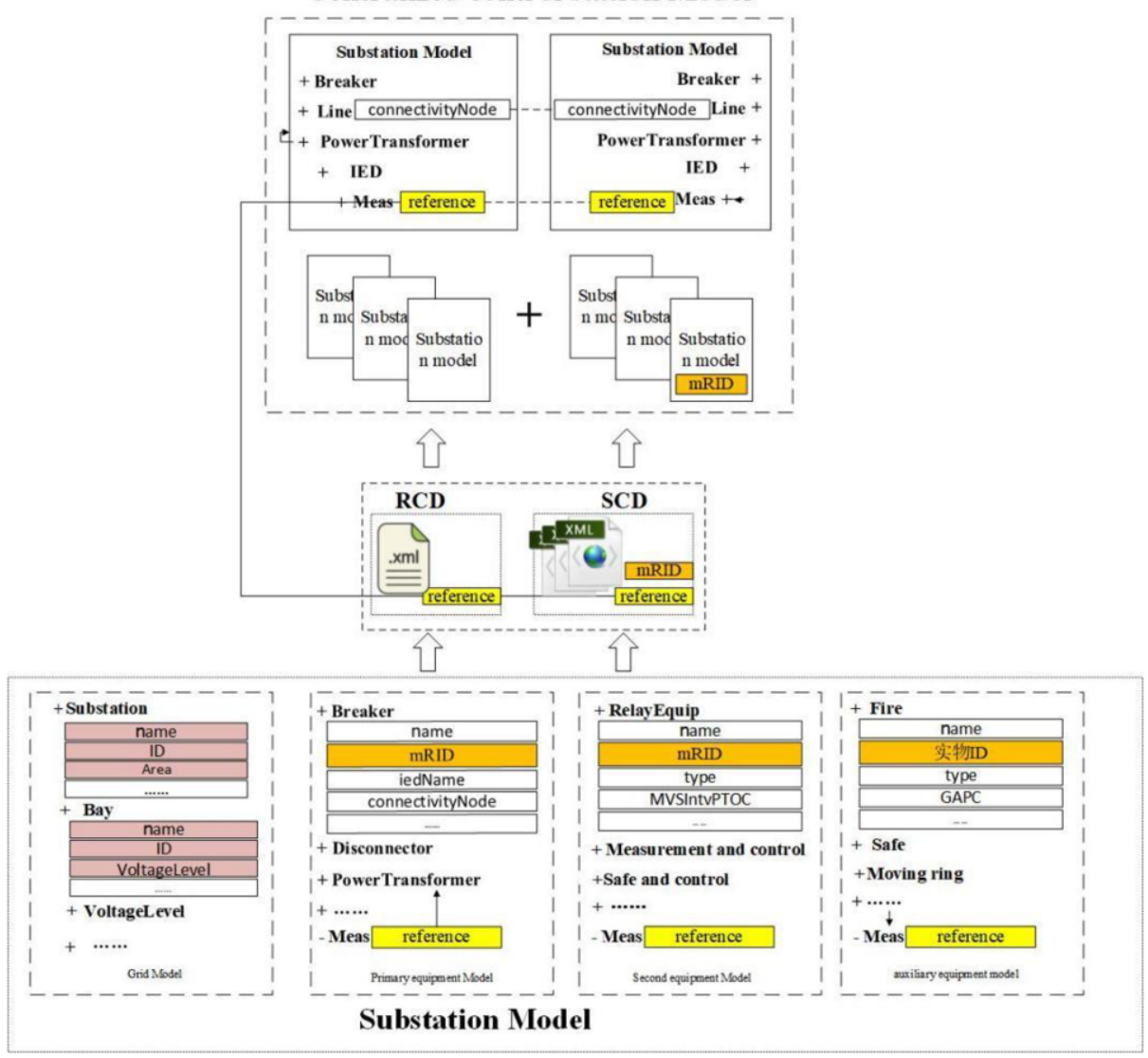

Figure 1. The first mock exam of substation unified model architecture.

\section{The Key Technology}

\subsection{Geographical Area Model}

The typical area division of substation is usually based on the principle of relatively independent physical area distribution. The typical area division is as follows: the surrounding wall is divided into five areas, and the wall with gate is divided into two areas according to the left and right wall of gate. According to the voltage level and equipment type, the primary equipment outdoor field can be divided into transformer outdoor field, $500 \mathrm{kV}$ outdoor field, $220 \mathrm{kV}$ outdoor field or $110 \mathrm{kV}$ outdoor field. Indoor primary switch gear, secondary equipment, station equipment, main control equipment, communication equipment and storage battery can be divided into $500 \mathrm{kV}$ protection room, $220 \mathrm{kV}$ protection room, $35 \mathrm{kV}$ high voltage room, station power distribution room, production complex building or main control room according to indoor relatively independent physical area. 
If a region is divided into several independent sub regions, the region can be divided into several sub regions. The sub region division is usually based on the principle of relatively independent physical region distribution. For example, the area of production complex building can include main control room, communication room, battery room, production preparation room, corridor and other sub areas. If an area is divided into floors, the identification and naming of each sub area should be able to distinguish the floors.

\subsection{Auxiliary Equipment Model}

Substation auxiliary equipment model should include fire protection, security, dynamic environment, video monitoring, online inspection and other equipment. IEC61850 describes primary equipment by conducting equipment class, and distinguishes specific equipment by attribute type. As shown in table $1, " \mathrm{CMR}$ " represents air conditioner.

Table 1. Classification table of auxiliary equipment.

\begin{tabular}{lcc}
\hline Classification & Auxiliary Equipment & Abbreviation \\
\hline Micro weather sensor & MCM \\
Temperature sensor & TMP \\
humidity sensor & HUM \\
Water immersion sensor & WIM \\
Water level sensor & WLL \\
SF6 monitoring sensor & QSF \\
Water pump & WPM \\
fighting control terminal & FMR \\
air conditioner & CMR \\
dehumidifier & DHR fan & SFF \\
\hline
\end{tabular}

The auxiliary control equipment is described by extending the device class, and the specific equipment is distinguished by the English abbreviation.

For the measuring point information of the auxiliary control equipment, it is described by LNode node, and the examples are as follows:

$<$ Device desc="Water spray fire extinguishing system" height="" length="" $\mathrm{mRID}="$ "" name="wsyl" position- $\mathrm{x}=$ "" position- $\mathrm{y}=$ "" position-z="" type="WSY" width="'">

$<$ LNode iedName="FFZ0001" ldInst="LD0" lnClass="GGIO" lnInst="1"

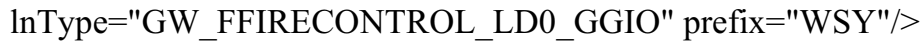

$</$ Device $>$ 


\subsection{IEC61850 Extension}

This paper extends the substation area model and auxiliary equipment model on the basis of IEC61850, as shown in Figure 2. The green box indicates the content of the extension. This paper extends the class; The hollow triangle represents the inheritance relationship; The solid diamond represents the inclusion relationship.

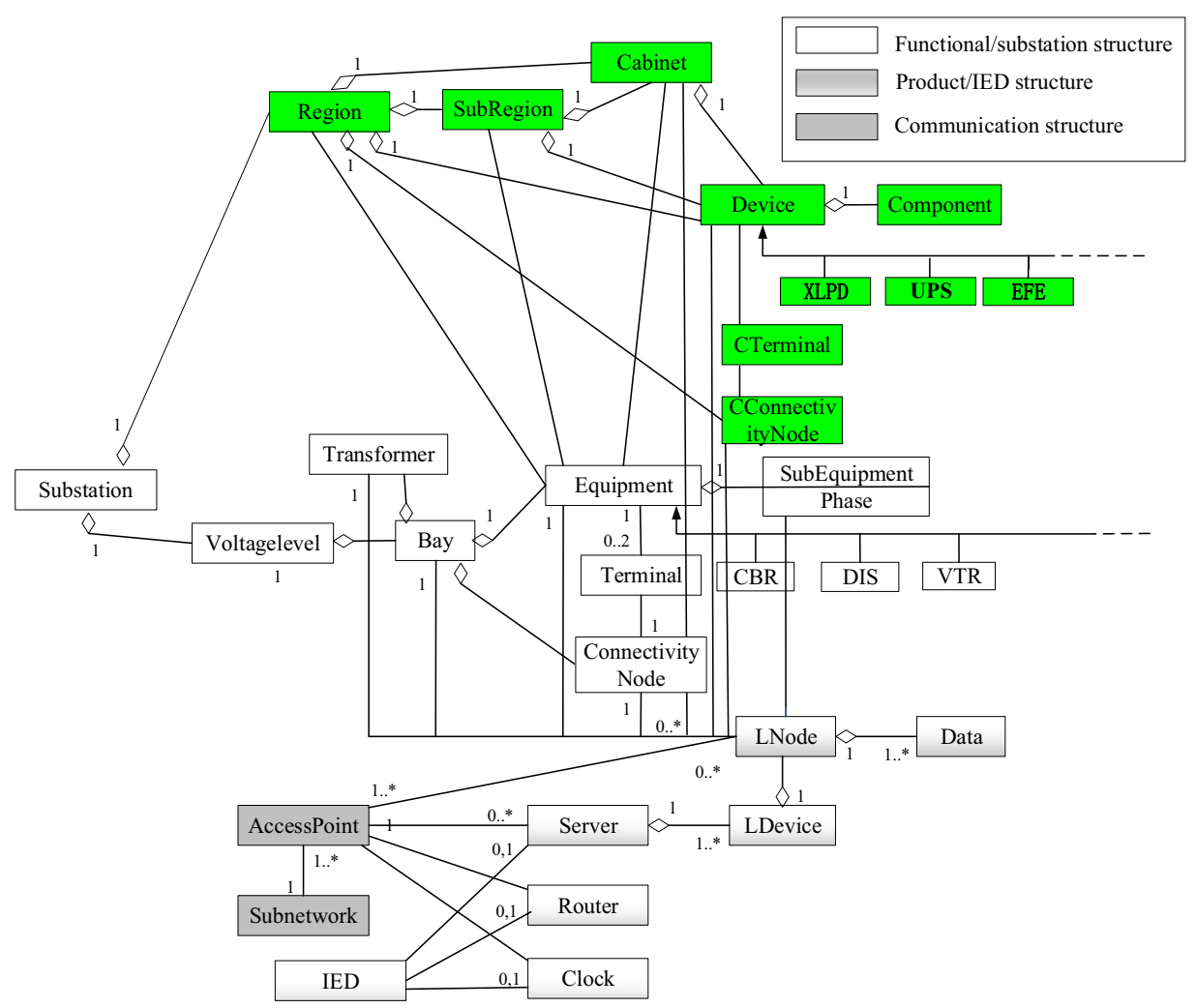

Figure 2. SSD structure diagram of Substation.

Firstly, the region class is added to describe the main area, such as "production complex building", and the extended sub region class is added to describe the sub areas, such as "first floor", "main control room" and so on. Cabinet description is added. Cabinet class, region class and sub region class belong to aggregation. Cabinet class must contain a sub region or a region. Add the device class to describe the auxiliary device.

The device class belongs to the aggregation relationship with the region, sub region and cabinet classes, and must include one of them. It describes the regional relationship of the auxiliary device, and describes the specific type of the auxiliary device through the type attribute. For example, "ups" stands for power supply, "CMR" stands for air conditioning. Examples are as follows:

$<$ Region name="region1" $\operatorname{desc}=$ "Production complex building" position- $\mathrm{x}=$ "" position-y="" position-z="" mRID="" substationName="shanghailu"> 
$<$ SubRegion name="subregion0" desc="1st floor" position- $\mathrm{x}=$ "" position$\mathrm{y}=$ "" position-z="" mRID="" length="'" width="" height="'>

$<$ SubRegion name="subregion 1 " desc="Main control room" position$\mathrm{x}=$ "' position-y="" position-z="" $\mathrm{mRID}=$ "' length="" width="" height="">

$<$ Device name="cmr1" desc="air conditioner" type="CMR" $\mathrm{mRID}=$ "" position- $\mathrm{x}=$ "" position- $\mathrm{y}=$ "' position-z="" length="" width="" height="'>

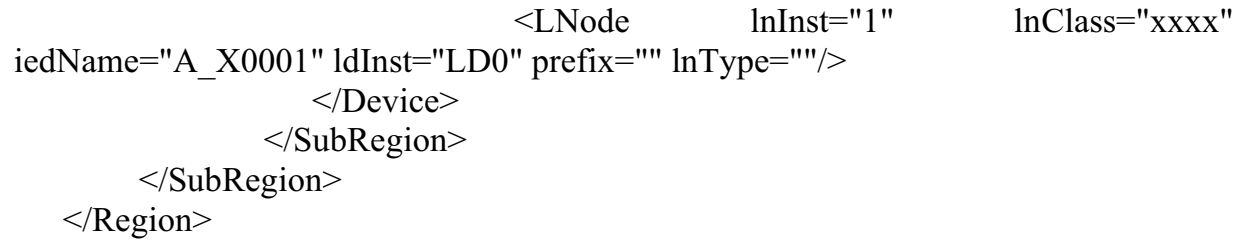

\section{Conclusion}

With the development and progress of technology, the interaction between master station and substation will be closer, and the content of interaction will be further improved. At present, IEC61850 standard lacks the description of substation area model and auxiliary equipment model, and the description of primary equipment in IEC61850 is relatively complete. Based on this idea, this paper puts forward the idea of extension of area model and auxiliary model, so as to be consistent with the standard as far as possible, and the extended part also conforms to the standard idea. This paper is an exploration of the extension of auxiliary model in IEC61850 standard. The development of any new technology is inseparable from the engineering application.

\section{References}

[1] Z L He. Relationship between intergrated automatic control system and power dispatching automation system [J]. Power System Technology, 2003, (03):68-70.

[2] Y Z Xin, J J Shi, J Y Zhou, et al. technology development trends of smart grid dispatching and control systems [J]. Automation of Electric Power Systems, 2015, 39(1):2-8.

[3] J G Yao, S C Yang, M H Shan. Reflections on operation supporting system architecture for future interconnected power grid [J]. Automation of Electric Power Systems, 2013, 37(21):52-59.

[4] A L Chen, F Ye, et al. A design method of database information model using IEC 61850 common data classes [J]. Automation of Electric Power Systems, 2013, 37(13):88-92.

[5] H D Zhang, H Zhang, et al. Model conversion method from smart substation SCD to control center CIM/E [J]. Automation of Electric Power Systems, 2012, 36(15):91-95.

[6] C Fan, Y M Ni, R H Dou, et al. Interpretation of relevant specifications of integrated supervision and control systems in smart substations [J]. Automation of Electric Power Systems, 2012, 36(19):1-5.

[7] D D Xu, W M Mi, Y Deng, et al. Integrated modeling for coordinated sharing of models/images and dispatch master substation [J]. Power System Technology, 2012, 36(11);235-239.

[8] F L Jin, H Wang, G M Fan, et al. Design of centralized substation monitoring functions for smart grid dispatching and control systems [J]. Automation of Electric Power Systems, 2015, 39(1):241-247.

[9] J L Li, Y Z Xin, G M Fan, et al. dynamic message coding technology of power systems [j]. automation of electric power systems, 2015, 39(1):14-18.

[10] S Q Hu, L Li, Z Qi, et al. Research on and application of IEC 61850 modelling and CIM extension for protection relay information management system [J]. Automation of Electric Power Systems, 2016, 40(6):119-125. 